\title{
The clinical relevance of oliguria in the critically ill patient: analysis of a large observational database
}

\author{
Jean-Louis Vincent ${ }^{1 *}$, Andrew Ferguson ${ }^{2}$, Peter Pickkers ${ }^{3}$, Stephan M. Jakob ${ }^{4}$, Ulrich Jaschinski ${ }^{5}$, \\ Ghaleb A. Almekhlafi ${ }^{6}$, Marc Leone ${ }^{7}$, Majid Mokhtari ${ }^{8}$, Luis E. Fontes ${ }^{9}$, Philippe R. Bauer ${ }^{10}$, Yasser Sakr ${ }^{11}$ for the \\ ICON Investigators
}

\begin{abstract}
Background: Urine output is widely used as one of the criteria for the diagnosis and staging of acute renal failure, but few studies have specifically assessed the role of oliguria as a marker of acute renal failure or outcomes in general intensive care unit (ICU) patients. Using a large multinational database, we therefore evaluated the occurrence of oliguria (defined as a urine output $<0.5 \mathrm{ml} / \mathrm{kg} / \mathrm{h}$ ) in acutely ill patients and its association with the need for renal replacement therapy (RRT) and outcome.
\end{abstract}

Methods: International observational study. All adult (> 16 years) patients in the ICON audit who had a urine output measurement on the day of admission were included. To investigate the association between oliguria and mortality, we used a multilevel analysis.

Results: Of the 8292 patients included, 2050 (24.7\%) were oliguric during the first $24 \mathrm{~h}$ of admission. Patients with oliguria on admission who had at least one additional 24-h urine output recorded during their ICU stay $(n=1349)$ were divided into three groups: transient_oliguria resolved within $48 \mathrm{~h}$ after the admission day $(n=390$ [28.9\%]), prolonged-oliguria resolved $>48 \mathrm{~h}$ after the admission day $(n=141[10.5 \%])$, and permanent-oliguria persisting for the whole ICU stay or again present at the end of the ICU stay $(n=818$ [60.6\%]). ICU and hospital mortality rates were higher in patients with oliguria than in those without, except for patients with transient oliguria who had significantly lower mortality rates than non-oliguric patients. In multilevel analysis, the need for RRT was associated with a significantly higher risk of death $(\mathrm{OR}=1.51[95 \% \mathrm{Cl} 1.19-1.91], p=0.001)$, but the presence of oliguria on admission was not $(\mathrm{OR}=1.14$ [95\% Cl 0.97-1.34], $p=0.103)$.

Conclusions: Oliguria is common in ICU patients and may have a relatively benign nature if only transient. The duration of oliguria and need for RRT are associated with worse outcome.

Keywords: Urine output, Renal replacement therapy, Mortality

\footnotetext{
* Correspondence: jlvincent@intensive.org

'Department of Intensive Care, Erasme University Hospital, Université Libre de Bruxelles, Route de Lennik, 808, 1070 Brussels, Belgium

Full list of author information is available at the end of the article
}

(c) The Author(s). 2020 Open Access This article is licensed under a Creative Commons Attribution 4.0 International License, which permits use, sharing, adaptation, distribution and reproduction in any medium or format, as long as you give appropriate credit to the original author(s) and the source, provide a link to the Creative Commons licence, and indicate if changes were made. The images or other third party material in this article are included in the article's Creative Commons licence, unless indicated otherwise in a credit line to the material. If material is not included in the article's Creative Commons licence and your intended use is not permitted by statutory regulation or exceeds the permitted use, you will need to obtain permission directly from the copyright holder. To view a copy of this licence, visit http://creativecommons.org/licenses/by/4.0/ The Creative Commons Public Domain Dedication waiver (http://creativecommons.org/publicdomain/zero/1.0/) applies to the data made available in this article, unless otherwise stated in a credit line to the data. 


\section{Introduction}

Regardless of the exact criteria used to define it, oliguria is often observed in critically ill patients, and yet there are many questions regarding its clinical relevance and impact on outcomes. Reduced urine output can be a physiological response or a reflection of altered tissue perfusion or renal dysfunction [1-3].

Although urine output is now widely used as one of the criteria for the diagnosis and staging of acute renal failure [4-7], there are relatively few studies that have specifically assessed urine output or oliguria as a marker of acute renal failure or outcomes in general populations of intensive care unit (ICU) patients $[2,8,9]$. The clinical importance of oliguria likely depends on its duration. For example, a 1 -h period of oliguria during an emergency admission is less important than if the symptom persists for longer periods, when it is more likely to reflect impaired renal function $[10,11]$.

To provide some global insight into the impact of oliguria and its persistence on outcomes in general ICU patients, we reviewed the large, international Intensive Care over Nations (ICON) database to evaluate the occurrence of oliguria and its association with the need for renal replacement therapy (RRT) and mortality.

\section{Patients and methods}

This study is a substudy of the ICON audit [12]. All adult (>16 years) patients admitted to a participating ICU (see the list in the "Acknowledgements") between May 8 and May 18, 2012, were included in the audit, except those who stayed in the ICU for $<24 \mathrm{~h}$ for routine postoperative surveillance. Participation was voluntary, with no financial incentive. Ethics committee approval was obtained by the participating institutions according to local ethical regulations.

Data were collected daily for a maximum of 28 days in the ICU and entered using electronic case report forms via a secured internet-based website. Survival data were collected at the time of ICU and hospital discharge, or at 60 days, whichever occurred first. Detailed instructions and definitions were available through a secured website for all participants before starting data collection and throughout the study period. Any additional queries were answered on a per case basis. Validity checks were made at the time of electronic data entry, including plausibility checks within each variable and between variables. Data were further reviewed by the coordinating center for completeness and plausibility, and any doubts clarified with the participating center. There was no onsite monitoring.

Data collection on admission included demographic data and comorbidities. Clinical and laboratory data for the SAPS II score [13] were reported as the worst values within the first $24 \mathrm{~h}$ after admission. A daily evaluation of organ function was performed according to the Sequential Organ Failure Assessment (SOFA) score [5]; organ failure was defined as a SOFA subscore $>2$ for the organ in question. ICU interventions, including RRT and mechanical ventilation, were recorded daily.

Clinical and microbiologically proven infections were reported daily as well as antimicrobial therapy. Infection was defined according to the criteria of the International Sepsis Forum [14]. Sepsis was defined as the presence of infection with associated organ failure [15]. Septic shock was defined as sepsis associated with cardiovascular failure requiring vasopressor support (SOFA cardiovascular score $\geq 3$ ). The presence of a decision to withhold/withdraw a life-sustaining measure at any time during the ICU stay was also recorded.

On the case report form, investigators recorded urine output in milliliters as a total for each 24-h period. On the day of admission, urine output data were recorded for the period from the time of admission till the start of the next ICU day. For the purposes of this study, oliguria was defined as a calculated urine output $<0.5 \mathrm{ml} / \mathrm{kg} / \mathrm{h}$ averaged over a 24-h period [2]. To calculate the urine output for the 24-h admission day period, if full urine output data for the first $24 \mathrm{~h}$ of admission were recorded, these data were used for the determination of oliguria "on admission." If data were provided for only $X$ hours on the day of admission (because, for example, the patient was admitted at $10 \mathrm{pm}$ and 24-h urine measurement started at midnight so only 2 -h urine output were noted), the estimation of urine output on admission was averaged from the data for the $X$ hours and the data from the first full day on the ICU (2nd day 24 -h urine output $/ 24 \times[24-X])$. If no data were recorded for the admission day, we were unable to estimate an admission urine output and the patient was not included. The methods of measuring urine output or of assessing body weight were not recorded. Patients with comorbid chronic renal failure were excluded.

For analysis of evolution during the ICU stay, we included only patients who had a urine output recorded on the day of admission and at least one other 24-h urine output value, and separated them into three groups:

- Transient oliguria-oliguria resolved within $48 \mathrm{~h}$ after the 24-h admission day

- Prolonged oliguria-oliguria resolved more than 48 $\mathrm{h}$ after the 24- $\mathrm{h}$ admission day and not present at the end of the ICU stay

- Permanent oliguria-oliguria present on the day of admission and persisting for the whole ICU stay or again present at the end of the ICU stay 


\section{Statistical analysis}

Data are shown as means with standard deviation (SD) or $95 \%$ confidence intervals (CI), medians and interquartile ranges (IQR), numbers, and percentages. For the descriptive statistics, only available data were used so missing data were subtracted from the denominator when calculating percentages. Differences between groups in distribution of variables were assessed using the analysis of variance (ANOVA), Kruskal-Wallis test, Student's $t$ test, Mann-Whitney test, chi-square test, or Fisher's exact test as appropriate.

Individual countries were classified into three income groups according to the 2011 gross national income (GNI) per capita, calculated using the World Bank Atlas method [16]: GNI < \$4035 = low and lower middle income, GNI \$4036-12,475=upper middle income, and GNI $>\$ 12,476=$ high income.

To investigate the association between oliguria on admission and mortality, we used a three-level technique with the structure of an individual patient (level 1) admitted to a specific hospital (level 2) within a particular country (level 3). So patients were nested within hospitals within countries. The model includes hospital and country units as random effects to express the concept that patients from the same country and treated in the same hospital share a common environment. The dependency between patients in a hospital within a country is captured through the use of random intercepts. The explanatory variables considered in the model were:

- Individual-level factors: age, sex, SAPS II score, type of admission, source of admission, highest concentration of creatinine, daily fluid balance, mechanical ventilation or RRT at any time during the ICU stay, fluid balance, presence of recorded end-of-life decision, comorbidities, severity of sepsis during the ICU stay, oliguria on admission

- Hospital-level factors: type of hospital, ICU specialty, total number of ICU patients in the previous year, number of staffed ICU beds

- Country-level factors: GNI

Collinearity between variables was checked by inspection of the correlation between them, by looking at the correlation matrix of the estimated parameters, and by looking at the change in parameter estimates and at their estimated standard errors [17]. Q-Q plots were drawn to check for normality in the residuals. The results of fixed effects (measures of association) are given as odds ratios (OR) with their 95\% CI. Random effects (measures of variation) measures included the variance (var) and its standard error (se). The restricted maximum likelihood (REML) procedure, which gives unbiased estimates of the model parameters, was used. The Wald test was used to assess the significance of included covariates. The percentage of cases correctly classified and the area under the receiver operating characteristic curve (AUC) are given to quantify the discriminating power of the model. Missing cases for the included variables were analyzed using the missingvalue indicator method.

Data were analyzed using IBM $^{\oplus}$ SPSS $^{\oplus}$ Statistics software, version 26 for Windows and $\mathrm{R}$ software, version 3.6.1 (CRAN project). All reported $p$ values are twosided, and a $p$ value $<0.05$ was considered to indicate statistical significance.

\section{Results}

Of the 10,069 patients included in the ICON audit, 9148 had urine output data on the day of admission; 856 had comorbid chronic renal failure and were excluded, leaving 8292 patients for analysis (Fig. 1).

\section{Patients with oliguria on admission}

A total of 2050 (24.7\%) patients had oliguria on the 24-h admission period, with a median urine output of 0.3 [IQR $0.1-0.4$ ] $\mathrm{ml} / \mathrm{kg} / \mathrm{h}$ compared to 1.1 [IQR $0.8-1.6$ ] $\mathrm{ml} / \mathrm{kg} / \mathrm{h}$ in patients who were not oliguric on admission $(p<0.001)$ (Table 1). Patients with oliguria on admission were older and more severely ill than those without, and a higher proportion had a medical diagnosis and comorbid heart failure, liver cirrhosis, and human immunodeficiency virus (HIV) infection (Table 1). They were more likely to have sepsis $(24.5 \%$ vs $16.7 \%$, $p<0.001$ ) and to have all forms of organ failure, except hepatic (Table 1). Vasopressor use was higher in patients with oliguria at admission than in those without $(36.9 \%$ vs $26.8 \%, p<0.001)$.

ICU $(26.8 \%$ vs $11.5 \%, p<0.001)$ and hospital $(34.5 \%$ vs $16.7 \%, p<0.001)$ mortality rates were more than twice as high in patients with oliguria on admission than in those without (Table 1). End-of-life decisions were more common in oliguric patients than in the other patients (Table 2).

RRT was needed at some point during the ICU stay in $442(21.6 \%)$ of the patients with and in $407(6.5 \%)$ of the patients without oliguria on admission $(p<0.001)$ (Table 2). Multilevel analysis revealed that the need for RRT was associated with a statistically significant increased risk of death (OR $=1.51$ [95\% CI 1.19-1.91], $p=$ $0.001)$, but the presence of oliguria on admission was not $(\mathrm{OR}=1.14$ [95\% CI 0.97-1.34], $p=0.103$ ) (Table 3). After controlling for patient and hospital factors and GNI, there was significant between-hospital (var $=0.5$ [se $=0.09], p<0.001$ ) and between-country (var $=0.23$ [se $=0.08$ ],$p=0.004$ ) variation in risks of in-hospital death (Table 3), indicating that the occurrence of inhospital death was influenced by both hospital- and country-related factors. 
10,069 patients $>16$ years old included in ICON

\section{Excluded: \\ 921 no urine output data \\ on admission}

\section{8 considered for analysis}

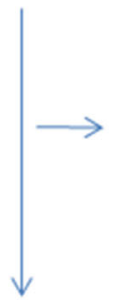

Excluded:

856 chronic renal

failure

\section{2 patients included in}

analysis of oliguria on admission

\section{2 (75.3\%) no oliguria}

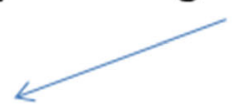

$2050(24.7 \%)$



Fig. 1 Flow chart of patients included in study

Persistence of oliguria during ICU stay

A total of 1349 patients had at least one additional urine output measurement recorded during their ICU stay. Oliguria was transient in 390 (28.9\%) of these patients, prolonged in 141 (10.5\%), and permanent in 818 (60.6\%) (Table 4). ICU mortality was $7.1 \%$ when oliguria was transient, significantly lower than in the patients without oliguria $(11.5 \%, p=0.037)$; rates were $10.9 \%$ when oliguria was prolonged and $28.9 \%$ when permanent (Table 4 ).
RRT was used in the ICU in 48 (12.3\%), 63 (44.7\%), and $273(33.4 \%)$ patients with transient, prolonged, and permanent oliguria, respectively; 102 (19\%) patients with permanent oliguria died in the ICU without receiving RRT. RRT was started within $24 \mathrm{~h}$ in $72.4 \%$ of patients with oliguria $(75.0 \%$ vs $73.0 \%$ vs $71.8 \%$ in patients with transient, prolonged, and permanent oliguria, respectively). Among patients receiving RRT, ICU mortality was higher in non-oliguric patients than in those with 
Table 1 Characteristics of the study cohort on admission to the ICU stratified according to whether or not oliguria was present

\begin{tabular}{|c|c|c|c|c|}
\hline & \multirow[t]{2}{*}{$\begin{array}{l}\text { All patients } \\
\boldsymbol{n}=8292\end{array}$} & \multicolumn{2}{|c|}{ Oliguria at admission } & \multirow[t]{2}{*}{$\boldsymbol{p}$ value } \\
\hline & & $\begin{array}{l}\text { No } \\
\boldsymbol{n}=6242(75.3 \%)\end{array}$ & $\begin{array}{l}\text { Yes } \\
\boldsymbol{n}=2050(24.7)\end{array}$ & \\
\hline Urine output $(\mathrm{ml} / \mathrm{kg} / \mathrm{h})$ median $[\mathrm{IQR}]$ & $0.9[0.5-1.4]$ & $1.1[0.8-1.6]$ & $0.3[0.1-0.4]$ & $<0.001$ \\
\hline Age, years, mean $\pm S D$ & $59.2 \pm 18.2$ & $58.1 \pm 18.3$ & $62.5 \pm 17.4$ & $<0.001$ \\
\hline Male, $n(\%)$ & $4928(60.0)$ & $3724(60.2)$ & $1204(59.4)$ & 0.55 \\
\hline \multicolumn{5}{|l|}{ Severity scores, mean \pm SD } \\
\hline SAPS II score & $40.8 \pm 17.5$ & $37.9 \pm 15.1$ & $49.8 \pm 20.8$ & $<0.001$ \\
\hline SOFA score at admission & $6.2 \pm 4.2$ & $5.7 \pm 3.8$ & $7.6 \pm 5.0$ & $<0.001$ \\
\hline SOFA score at admission (without renal subscore) & $5.3 \pm 3.7$ & $5.1 \pm 3.5$ & $5.8 \pm 4.2$ & $<0.001$ \\
\hline \multicolumn{5}{|l|}{ Type of admission, $n$ (\%) } \\
\hline Surgical (non-trauma) & $2939(37.2)$ & $2374(39.9)$ & $565(29.2)$ & \multirow[t]{4}{*}{$<0.001$} \\
\hline Medical & $4335(54.9)$ & $3063(51.4)$ & $1272(65.7)$ & \\
\hline Trauma & $569(7.2)$ & $478(8.0)$ & $91(4.7)$ & \\
\hline Other & $48(.6)$ & $40(.7)$ & $8(.4)$ & \\
\hline \multicolumn{5}{|l|}{ Source of admission, $n$ (\%) } \\
\hline Other hospital & $825(9.9)$ & $625(10.0)$ & $200(9.8)$ & \multirow[t]{5}{*}{$<0.01$} \\
\hline ER/ambulance & $3151(38.0)$ & $2336(37.4)$ & $815(39.8)$ & \\
\hline OR/recovery room & $1569(18.9)$ & $1304(20.9)$ & $265(12.9)$ & \\
\hline Hospital floor & $2117(25.5)$ & $1529(24.5)$ & $588(28.7)$ & \\
\hline Other & $630(7.6)$ & $448(7.2)$ & $182(8.9)$ & \\
\hline \multicolumn{5}{|l|}{ Comorbidities, n (\%) } \\
\hline COPD & $1012(12.2)$ & $737(11.8)$ & $275(13.4)$ & 0.06 \\
\hline Cancer & $891(10.7)$ & $684(11.0)$ & $207(10.1)$ & 0.29 \\
\hline Metastatic cancer & $288(3.5)$ & $205(3.3)$ & $83(4.0)$ & 0.11 \\
\hline Hematologic cancer & $178(2.1)$ & $126(2.0)$ & $52(2.5)$ & 0.16 \\
\hline Insulin & $682(8.2)$ & $496(7.9)$ & $186(9.1)$ & 0.12 \\
\hline Heart failure, NYHA III/IV & $648(7.8)$ & $445(7.1)$ & $203(9.9)$ & $<0.001$ \\
\hline HIV infection & $56(.7)$ & $33(.5)$ & $23(1.1)$ & $<0.01$ \\
\hline Cirrhosis & $283(3.4)$ & $188(3.0)$ & $95(4.6)$ & $<0.001$ \\
\hline Immunosuppression & $259(3.1)$ & $184(2.9)$ & $75(3.7)$ & 0.11 \\
\hline Steroid therapy & $273(3.3)$ & $208(3.3)$ & $65(3.2)$ & 0.78 \\
\hline Chemotherapy & $239(2.9)$ & $181(2.9)$ & $58(2.8)$ & 0.94 \\
\hline \multicolumn{5}{|l|}{ Organ support, $n(\%)$} \\
\hline Mechanical ventilation & $4227(51.0)$ & $3184(51.0)$ & $1043(50.9)$ & 0.92 \\
\hline Renal replacement therapy & $321(3.9)$ & $97(1.6)$ & $224(10.9)$ & $<0.001$ \\
\hline Vasopressor use & $2429(29.3)$ & $1672(26.8)$ & $757(36.9)$ & $<0.001$ \\
\hline \multicolumn{5}{|l|}{ Type of organ failure, $n$ (\%) (alone or in combination) } \\
\hline Respiratory & $1867(22.5)$ & $1334(21.4)$ & $533(26.0)$ & $<0.001$ \\
\hline Coagulation & $530(6.4)$ & $345(5.5)$ & $185(9.0)$ & $<0.001$ \\
\hline Hepatic & $885(10.7)$ & $658(10.5)$ & $227(11.1)$ & 0.51 \\
\hline CNS & $1972(23.8)$ & $1435(23.0)$ & $537(26.2)$ & $<0.01$ \\
\hline Renal & $1341(16.2)$ & $524(8.4)$ & 817 (39.9) & $<0.001$ \\
\hline Cardiovascular & $2296(27.7)$ & $1580(25.3)$ & 716 (34.9) & $<0.001$ \\
\hline
\end{tabular}


Table 1 Characteristics of the study cohort on admission to the ICU stratified according to whether or not oliguria was present (Continued)

\begin{tabular}{|c|c|c|c|c|}
\hline & \multirow[t]{2}{*}{$\begin{array}{l}\text { All patients } \\
\boldsymbol{n}=8292\end{array}$} & \multicolumn{2}{|c|}{ Oliguria at admission } & \multirow[t]{2}{*}{$\boldsymbol{p}$ value } \\
\hline & & $\begin{array}{l}\text { No } \\
\boldsymbol{n}=6242(75.3 \%)\end{array}$ & $\begin{array}{l}\text { Yes } \\
\boldsymbol{n}=2050(24.7)\end{array}$ & \\
\hline \multicolumn{5}{|c|}{ Number of organ failures, $n(\%)$} \\
\hline None & $1771(21.4)$ & $1489(23.9)$ & $282(13.8)$ & \multirow[t]{5}{*}{$<0.001$} \\
\hline 1 organ & $2344(28.3)$ & $1805(28.9)$ & $539(26.3)$ & \\
\hline 2 organs & $1693(20.4)$ & $1302(20.9)$ & $391(19.1)$ & \\
\hline 3 organs & $1231(14.8)$ & $883(14.1)$ & $348(17.0)$ & \\
\hline$>3$ organs & $1253(15.1)$ & $763(12.2)$ & $490(23.9)$ & \\
\hline Sepsis, $n(\%)$ & $1543(18.6)$ & $1041(16.7)$ & $502(24.5)$ & $<0.001$ \\
\hline ICU stay, median [IQR] & $3.0[2.0-6.0]$ & $3.0[2.0-6.0]$ & $3.0[1.0-7.0]$ & $<0.001$ \\
\hline In survivors & $3.0[1.0-6.0]$ & $3.0[1.0-6.0]$ & $3.0[0.0-7.0]$ & 0.046 \\
\hline In non-survivors & $3.0[0.0-8.0]$ & $5.0[1.0-10.0]$ & $2.0[0.0-6.0]$ & $<0.001$ \\
\hline Hospital stay, median [IQR] & $10.0[5.0-20.0]$ & $10.0[6.0-20.0]$ & $8.0[2.0-18.0]$ & $<0.001$ \\
\hline In survivors & $11.0[2.0-21.0]$ & $11.0[2.0-21.0]$ & $11.0[1.0-22.0]$ & 0.075 \\
\hline In non-survivors & $5.0[0.0-14.0]$ & $7.0[1.0-15.0]$ & $3.0[0.0-10.0]$ & $<0.001$ \\
\hline ICU mortality, n (\%) & $1234(15.2)$ & $700(11.5)$ & $534(26.8)$ & $<0.001$ \\
\hline Hospital mortality, n (\%) & $1649(21.1)$ & $983(16.7)$ & $666(34.5)$ & $<0.001$ \\
\hline
\end{tabular}

transient or prolonged oliguria but lower than in those with permanent oliguria (Table 4). The maximum serum creatinine concentration was higher in patients with prolonged and permanent oliguria than in those with transient oliguria (Table 4). The mean daily fluid balance during the ICU stay was significantly higher in patients with permanent oliguria than in those with transient or prolonged oliguria (Table 4).

\section{Discussion}

The present study in a large cohort of ICU patients with urine outputs measured on admission and during the

Table 2 Interventions and occurrence of sepsis during the ICU stay

\begin{tabular}{|c|c|c|c|c|}
\hline & \multirow{2}{*}{$\begin{array}{l}\text { All patients } \\
\boldsymbol{n}=8292\end{array}$} & \multicolumn{2}{|l|}{ Oliguria } & \multirow{2}{*}{$\begin{array}{l}p \\
\text { value }\end{array}$} \\
\hline & & $\begin{array}{l}\text { No } \\
\boldsymbol{n}=6242(75.3 \%)\end{array}$ & $\begin{array}{l}\text { Yes } \\
\boldsymbol{n}=2050(24.7 \%)\end{array}$ & \\
\hline Creatinine, highest concentration (mg/dl), median [IQR] & $1.0[0.8-1.5]$ & $0.9[0.7-1.3]$ & $1.3[0.9-2.4]$ & $<0.001$ \\
\hline Daily fluid balance ${ }^{a}$, ml, median [IQR] & $81.0[-504.1-730.4]$ & $3.3[-612-605.7]$ & $356.3[-153.2-1116.7]$ & $<0.001$ \\
\hline Mechanical ventilation, $n$ (\%) & $4769(57.5)$ & $3579(57.3)$ & $1190(58.0)$ & 0.59 \\
\hline RRT, $n(\%)$ & $849(10.2)$ & $407(6.5)$ & $442(21.6)$ & $<0.001$ \\
\hline Hemofiltration, $n(\%)$ & $590(7.1)$ & $268(4.3)$ & $322(15.7)$ & $<0.001$ \\
\hline Hemodialysis, $n(\%)$ & $551(6.6)$ & $266(4.3)$ & $285(13.9)$ & $<0.001$ \\
\hline \multicolumn{5}{|l|}{ Sepsis severity, $n(\%)$} \\
\hline No sepsis & $5718(69)$ & $4403(70.5)$ & $1315(64.1)$ & \multirow[t]{3}{*}{$<0.001$} \\
\hline Sepsis & $1104(13.3)$ & $858(13.7)$ & $246(12.0)$ & \\
\hline Shock & $1470(17.7)$ & $981(15.7)$ & $489(23.9)$ & \\
\hline Decision to withhold/withdraw life-sustaining therapy, $n$ (\%) & $1068(12.9)$ & $728(11.7)$ & $340(16.6)$ & $<0.001$ \\
\hline
\end{tabular}

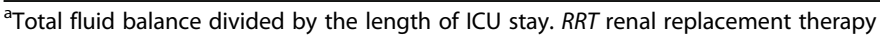


Table 3 Multilevel analysis of factors associated with hospital mortality

\begin{tabular}{|c|c|c|}
\hline Variables & OR $(95 \% \mathrm{Cl})$ & $\boldsymbol{p}$ value \\
\hline \multicolumn{3}{|l|}{ Fixed effects, varying within clusters } \\
\hline Age & $1.00(1.00-1.01)$ & 0.19 \\
\hline Sex, male & $0.99(0.85-1.14)$ & 0.848 \\
\hline SAPS $\|$ & $1.05(1.05-1.06)$ & $<0.001$ \\
\hline \multicolumn{3}{|l|}{ Type of admission (\%) } \\
\hline Surgical & Ref & na \\
\hline Medical & $1.53(1.26-1.86)$ & $<0.001$ \\
\hline Trauma & $1.53(1.14-2.05)$ & 0.004 \\
\hline Other & $1.92(0.71-5.17)$ & 0.196 \\
\hline \multicolumn{3}{|l|}{ Source of admission } \\
\hline OR/recovery & Ref & na \\
\hline Other hospital & $1.17(0.81-1.68)$ & 0.404 \\
\hline ER/ambulance & $1.12(0.84-1.49)$ & 0.458 \\
\hline Hospital floor & $1.65(1.26-2.16)$ & $<0.001$ \\
\hline Other & $1.20(0.81-1.80)$ & 0.366 \\
\hline \multicolumn{3}{|l|}{ Comorbidities } \\
\hline COPD & $0.98(0.73-1.31)$ & 0.877 \\
\hline Cancer & $1.41(1.15-1.74)$ & 0.001 \\
\hline Metastatic cancer & $1.20(0.86-1.67)$ & 0.281 \\
\hline Hematologic cancer & $1.75(1.25-2.44)$ & 0.001 \\
\hline Insulin & $0.84(0.64-1.09)$ & 0.189 \\
\hline Heart failure, NYHA III/IV & $1.54(1.19-1.99)$ & 0.001 \\
\hline HIV infection & $0.73(0.27-1.94)$ & 0.523 \\
\hline Cirrhosis & $2.12(1.45-3.10)$ & $<0.001$ \\
\hline Immunosuppression & $1.19(0.78-1.79)$ & 0.419 \\
\hline Steroid therapy & $1.17(0.74-1.84)$ & 0.497 \\
\hline Chemotherapy & $0.92(0.55-1.53)$ & 0.748 \\
\hline Creatinine, highest [mg/dl] & $1.00(0.97-1.02)$ & 0.796 \\
\hline Daily fluid balance ${ }^{a}[l]$ & $1.37(1.25-1.50)$ & $<0.001$ \\
\hline \multicolumn{3}{|l|}{ Procedures during the ICU stay } \\
\hline Mechanical ventilation & $2.66(2.12-3.34)$ & $<0.001$ \\
\hline Renal replacement therapy & $1.51(1.19-1.91)$ & 0.001 \\
\hline \multicolumn{3}{|l|}{ Severity of sepsis } \\
\hline No sepsis & Ref & na \\
\hline Sepsis without shock & $0.98(0.75-1.28)$ & 0.887 \\
\hline Septic shock & $1.55(1.25-1.92)$ & $<0.001$ \\
\hline End-of-life decision & $11.82(6.70-20.84)$ & $<0.001$ \\
\hline Oliguria on admission & $1.14(0.97-1.34)$ & 0.103 \\
\hline \multicolumn{3}{|c|}{ Fixed effects, constant within clusters } \\
\hline \multicolumn{3}{|l|}{ Type of hospital } \\
\hline University/academic & Ref & na \\
\hline Non-university & $1.16(0.88-1.52)$ & 0.293 \\
\hline
\end{tabular}

Table 3 Multilevel analysis of factors associated with hospital mortality (Continued)

\begin{tabular}{|c|c|c|}
\hline Variables & OR $(95 \% \mathrm{Cl})$ & $\boldsymbol{p}$ value \\
\hline \multicolumn{3}{|c|}{ Number of patients admitted to the ICU (in 2011) } \\
\hline $750+$ & Ref & na \\
\hline $500-749$ & $0.95(0.76-1.19)$ & 0.663 \\
\hline 250-499 & $0.95(0.68-1.31)$ & 0.746 \\
\hline$<250$ & $1.21(0.77-1.91)$ & 0.415 \\
\hline \multicolumn{3}{|l|}{ ICU specialty } \\
\hline Surgical & Ref & na \\
\hline Medical & $0.63(0.38-1.04)$ & 0.072 \\
\hline Mixed & $0.73(0.54-1.00)$ & 0.047 \\
\hline Others & $0.94(0.58-1.52)$ & 0.79 \\
\hline \multicolumn{3}{|l|}{ Staffed ICU beds } \\
\hline $15+$ & Ref & na \\
\hline$<15$ & $1.12(0.87-1.44)$ & 0.397 \\
\hline \multicolumn{3}{|l|}{ Income } \\
\hline High & Ref & na \\
\hline Upper middle & $1.81(1.20-2.73)$ & 0.005 \\
\hline Low and lower middle & $2.05(1.37-3.08)$ & 0.001 \\
\hline \multicolumn{3}{|l|}{ Random effects } \\
\hline \multicolumn{3}{|l|}{ Country } \\
\hline Variance (se) & $0.23(0.08)$ & \\
\hline$p$ value & 0.004 & \\
\hline \multicolumn{3}{|l|}{ Hospital within country } \\
\hline Variance (se) & $0.50(0.09)$ & \\
\hline$p$ value & $<0.001$ & \\
\hline
\end{tabular}

${ }^{\mathrm{a}}$ Total fluid balance divided by the length of ICU stay OR odds ratio, SAPS // Simplified Acute Physiology Score II, ER emergency room, $O R$ operating room, COPD chronic obstructive pulmonary disease, NYHA New York Heart Association, HIV human immunodeficiency virus. The percentage of cases correctly classified with this model is $88.6 \%$. The AUC is 91.5\% (95\% Cl 90.7-92.3\%)

ICU stay reveals that oliguria is present in about one fourth of critically ill patients on admission to the ICU. The presence of oliguria on admission was not independently associated with an increased risk of death, but the persistence of oliguria during the ICU stay was associated with higher ICU and hospital mortality rates.

There are relatively few published data on the frequency of oliguria in general ICU patients. Oliguria is frequently observed in the perioperative period and may be the consequence of hypovolemia and/or pain, both triggering the sympathetic nervous system, which in turn lead to activation of the renin-angiotensin-aldosterone system with ensuing oliguria. However, oliguria may also represent a warning of deteriorating renal function, especially in critically ill patients. Macedo et al. reported that $47 \%$ of their cohort of 317 surgical ICU patients had an episode of oliguria (urine output $<0.5 \mathrm{ml} / \mathrm{kg} / \mathrm{h}$ for at least 6 consecutive 
Table 4 Creatinine concentrations, fluid balance, renal replacement therapy, and mortality rates in patients with transient, prolonged, and permanent oliguria

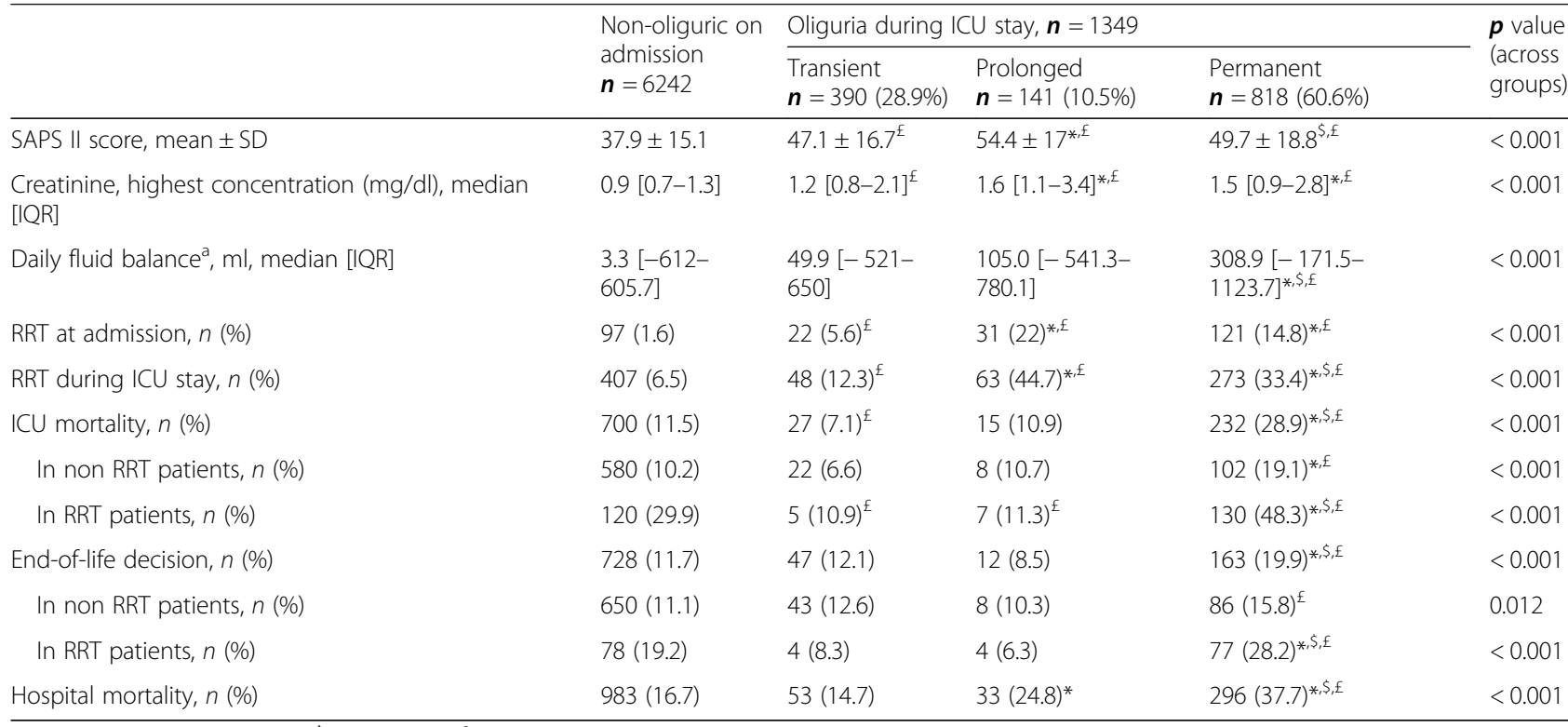

Pairwise $p$ values: *vs transient; ${ }^{5}$ vs prolonged; ${ }^{f}$ vs non-oliguric on admission. ${ }^{\text {a }}$ Total fluid balance divided by the length of ICU stay. IQR interquartile range, $R R T$ renal replacement therapy, ICU intensive care unit. Percentages are calculated after excluding missing data

hours) during the ICU stay [1]. In an analysis of data from the FINNAKI study, as many as $92 \%$ of patients had an episode of oliguria as defined by a urine output $<0.5 \mathrm{ml} /$ $\mathrm{kg} / \mathrm{h}$ for a minimum of $0.5 \mathrm{~h} \mathrm{[3].} \mathrm{From} \mathrm{their} \mathrm{large} \mathrm{data-}$ base, Kellum et al. reported that $59 \%$ of ICU patients with acute kidney injury (AKI) met the KDIGO urine output criteria [8]. In a smaller cohort, Md Ralib et al. reported that $61 \%$ of patients with AKI met urine output criteria $(<$ $0.5 \mathrm{ml} / \mathrm{kg} / \mathrm{h}$ ) [11], and in a study of critically ill cancer patients, 56\% met urine output criteria for AKI [18].

The mortality rate was higher in patients with oliguria than in those without. In an analysis of 21,207 ICU patients from the large MIMIC-II database, Zhang et al. similarly reported increased mortality in patients with oliguria on day 1 [19]. However, oliguria may be an epiphenomenon of or surrogate for disease severity and after adjusting for multiple factors in the multilevel analysis, oliguria on admission was not independently associated with increased mortality in our patients. Importantly, we also analyzed the persistence of oliguria during the ICU stay and noted that ICU mortality rates in patients with transient oliguria were significantly lower than those in nonoliguric patients. Indeed, ICU and hospital mortality rates were lower in these patients with transient oliguria than in the overall ICON cohort (ICU $16.2 \%$, hospital $22.4 \%$, both $p<0.001$ ) [12]. Our results therefore highlight that the duration of oliguria seems to be more important than the presence of oliguria per se. Macedo et al. similarly reported that prolonged duration of oliguria $(>12 \mathrm{~h}$ ) was associated with increased mortality [1]. Vaara et al. [3] reported that $6-12 \mathrm{~h}$ of oliguria $(0.3$ to $<0.5 \mathrm{ml} / \mathrm{kg} / \mathrm{h}),>6$ h of oliguria ( 0.1 to $<0.3 \mathrm{ml} / \mathrm{kg} / \mathrm{h}$ ), and severe oliguria $(<0.1 \mathrm{ml} / \mathrm{kg} / \mathrm{h})$ lasting $>3 \mathrm{~h}$ were independently associated with increased 90-day mortality. In an earlier analysis of the ICON database, patients who remained in stage 3 AKI (defined using the AKIN urine output or creatinine criteria) for a 7-day period had higher mortality rates than those in whom renal function recovered [20]. Prowle et al. [2] noted that although oliguria of longer than $1 \mathrm{~h}$ was significantly associated with the subsequent development of AKI diagnosed using creatinine criteria, short periods (1-6 h) of oliguria were not accurate at predicting AKI. In a cohort of patients undergoing major abdominal surgery, the presence of oliguria (urine output $<0.3 \mathrm{ml} / \mathrm{kg} / \mathrm{h}$ ) during surgery was indicative of an elevated probability of later AKI [21]. Similar results were recently published by Myles et al. [22] when a urine output $<0.5 \mathrm{ml} / \mathrm{kg} / \mathrm{h}$ was used to define oliguria.

Our data also suggest that the increased mortality may be related more to the need for RRT than the oliguria itself, suggesting that other parameters, for example, high serum creatinine concentrations, may be better indicators for RRT than urine output. In an analysis of the MIMIC-II database, Mandelbaum et al. [9] reported that the increase in serum creatinine was a better predictor of the need for RRT than urine output, although urine output was a slightly better predictor of mortality. In their analysis, Kellum et al. reported that RRT use was more likely in patients diagnosed with AKI using urine output and creatinine concentration criteria than in patients diagnosed with AKI using just one of the two criteria [8]. We did not use the AKI criteria, preferring to 
use the more global term of "acute renal failure" (defined by a renal SOFA score $>2$ ) and need for RRT, because this puts the degree of renal impairment in relation to the dysfunction of the other organs. The SOFA criteria are actually more commonly used than AKI in the critical care literature [23]. Somewhat surprisingly, in the current analysis, RRT was used in only $33 \%$ of the patients with permanent oliguria; however, $66 \%$ of the patients with permanent oliguria who did not receive RRT were discharged to the hospital floor or another hospital and we have no information about ongoing patient management after ICU discharge. Patients with permanent oliguria were also more likely to have a recorded decision to withhold/withdraw a life-sustaining measure, possibly explaining why RRT was not used in some of these patients.

Recovery of a urine output is not itself a predictive factor, and urine output is not helpful in guiding fluid resuscitation [24]. Patients with permanent oliguria had a more positive fluid balance than those with transient or prolonged oliguria, which may explain in part the higher mortality rates in these patients, although it is not possible to determine whether these observations are epiphenomena or causal effects. Vaara et al. demonstrated an association between cumulative fluid overload (fluid accumulation $>10 \%$ ) prior to RRT initiation and increased risk for 90-day mortality; the 90-day mortality rate of patients with fluid overload was $59.2 \%$ versus $31.4 \%$ without (difference of $27.8 \%, p<0.001$ ) [25]. In an earlier analysis of the ICON database, we reported that fluid balances became negative after the third ICU day in survivors but remained positive in non-survivors and that higher cumulative fluid balance at day 3 after ICU admission was independently associated with an increase in the hazard of death [26]. However, large randomized controlled trials have not shown a significant impact of fluid resuscitation strategy on clinical outcome or need for RRT [27].

Our study has several strengths but also some limitations. Strengths include the large database with patients from around the world, providing external validity, and the collection of data during the ICU stay. Limitations include the complexity of elements associated with oliguria that cannot be separated out, for example, we were unable to assess the need for fluids or diuretics or to assess the impact of different vasopressors. Moreover, criteria for RRT were not pre-defined due to the study design. Thus, RRT may have been used for fluid overload, increased urea and creatinine concentrations, electrolyte abnormalities, severe acidosis, and any combination of these. Another limitation is the lack of preadmission data regarding the length of oliguria prior to ICU admission or the underlying reason for oliguria as well as the lack of post-discharge data. The methods of monitoring urine output and assessing body weight also likely varied across centers and may have influenced the accuracy of measurements. Finally, we chose a definition of oliguria using a cut-off of urine output of $0.5 \mathrm{ml} / \mathrm{kg} / \mathrm{h}$, but this degree of urine output may in fact be adequate for some patients, e.g., the very obese and the very old.

\section{Conclusion}

In conclusion, the present study demonstrates that oliguria is a common occurrence in ICU patients, and suggests that it may have a relatively benign nature if only transient. For prognostic assessment, it is more the duration of oliguria and need for RRT than oliguria per se that are associated with a worse outcome.

\section{Abbreviations}

AKI: Acute kidney injury; GNI: Gross national income; ICU: Intensive care unit; KDIGO: Kidney Disease Improving Global Outcomes; RRT: Renal replacement therapy; SOFA: Sequential Organ Failure Assessment

\section{Acknowledgements}

We would like to thank Hassane Njimi, MSc, PhD, Department of Intensive Care, Erasme University Hospital, Brussels, Belgium, for his help with the statistical analyses.

We also acknowledge the investigators at our participating centers: Angola: Clinica Sagrada Esperança (Esmael Tomas)

Democratic Republic of Congo: Cliniques Universitaires De Kinshasa (Eric Amisi Bibonge)

Morocco: Chu Ibn Rochd Casablanca (Boubaker Charra); Ibn Sina Hospital (Mamoun Faroudy)

South Africa: Chris Hani Baragwanath Academic Hospital (Linda Doedens); Grey's Hospital (Zane Farina); Sandton Medi Clinic (David Adler); Tygerberg Hospital (Cecile Balkema); Union Hospital Alberton (Adri Kok)

Tunisia: Bizerte Hospital (Sami Alaya); Military Hospital of Tunis (Hedi Gharsallah)

Albania: National Trauma Centre and Military Hospital, Tirana (Dritan Muzha) Bulgaria: Alexandrovska University Hospital (Atanas Temelkov); Emergency University Hospital 'Pirogov' (Georgi Georgiev); Tokuda Hospital Sofia (Georgi Simeonov); Un St Ekaterina Sofia (Georgi Tsaryanski); University Hospital for

Obstetrics and Gynaecology (Silvi Georgiev); University Hospital Sveta Marina - Varna (Ali Seliman)

Croatia: General Hosp. Sibenik (Srdan Vrankovic); University Hospital Centre "Sestre Milosrdnice" (Zeljko Vucicevic); University Hospital Centre Zagreb (Ivan Gornik); University Hospital for Infectious Diseases (Bruno Barsic); University Hospital Dubrava (Ino Husedzinovic)

Czech Republic: Centre of Cardiovascular and Transplant Surgery (Pavel Pavlik); Charles University Hospital (Jan Manak); IKEM, Praque (Eva Kieslichova); KNTB Zlín A.S. (Radovan Turek); Krajska Nemocnice Liberec (Michal Fischer); Masarykova Nemocnice V Usti Nad Labem (Radka Valkova); St. Anne's University Hospital Brno (Lukas Dadak); University Hospital Haradec Králové (Pavel Dostal); University Hospital Brno (Jan Malaska); University Hospital Olomouc (Roman Hajek); University Hospital Plzen (Alexandra

Židková); Charles University Hospital Plzen (Pavel Lavicka)

Estonia: Tartu University Hospital (Joel Starkopf)

Georgia: Critical Care Medicine Institute (Zurab Kheladze); Jo Ann Medical Centre (Mamuka Chkhaidze); Kipshidze Central University Hospital (Vakhtang Kaloiani)

Hungary: Dr. Kenessey Albert Hospital (Laszlo Medve); Fejér County St George Teaching Hospital (Agnes Sarkany); Flor Ferenc County Hospital (Ildiko Kremer); Jávorszky Ödön Hospital (Zsuzsa Marjanek); Peterfy Hospital Budapest (Peter Tamasi)

Latvia: Infectology Centre of Latvia (Inga Krupnova); Paul Stradins Clinical University Hospital (Indulis Vanags); Riga East Clinical University Hospital (Viesturs Liguts)

Lithuania: Hospital of Lithuanian University of Health Sciences Kauno Klinikos (Vidas Pilvinis); Vilnius University Hospital (Saulius Vosylius); Vilnius University 
Hospital "Santariskiu Clinics", HSICU (Gintautas Kekstas); Vilnius University Hospital Santariskiu Clinics, CICU (Mindaugas Balciunas)

Poland: Csk Mswia (Julia Kolbusz); Medical University (Andrzej Kübler); Medical University Of Wroclaw (Beata Mielczarek); Medical University Warsaw (Malgorzata Mikaszewska-Sokolewicz); Pomeranian Medical University (Katarzyna Kotfis); Regional Hospital in Poznan (Barbara Tamowicz); Szpital Powiatowy W Ostrowi Mazowieckiej (Wiktor Sulkowski); University Hospital, Poznam (Piotr Smuszkiewicz); Wojewódzki Szpital Zakazny (Andrzej Pihowicz); Wojewódzkie Centrum Medyczne (Ewa Trejnowska) Romania: Emergency County Hospital Cluj (Natalia Hagau); Emergency Institute for Cardiovascular Diseases (Daniela Filipescu); Fundeni Clinical Institute (Gabriela Droc); Galati Hospital (Mary Nicoleta Lupu); Inbi "Prof. Dr. Matei Bals" (Alexandru Nica); Institute of Pulmonology Marius Nasta (Radu Stoica); Institutul Clinic Fundeni (Dana Rodica Tomescu); Sfantul Pantelimon Hospital (Dacia Laurentia Constantinescu); Spitalul Cf 2 Bucuresti (Georgica M Valcoreanu Zbaganu); "Luliu Hatieganu" University of Medicine and Pharmacy, Teaching Hospital of Infectious Diseases, Cluj-Napoca (Adriana Slavcovici)

Russia: City Clinical Hospital No 40 (Vladmir Bagin); City Hospital No 40 (Dmitry Belsky); Clinical Hospital N.A. N.V.Solovyev (Shamil Palyutin); Emergency Research Institute N.A. Djanelidze (Sergey Shlyapnikov); Federal Research Centre Paediatric Haematology, Oncology and Immunology (D Bikkulova); Krasnoyarsk State Medical University, Krasnoyarsk Regional Hospital (Alexey Gritsan); Medical Association "Novaya Bolnitsa" (Gulyaeva Natalia); Military Medical Academy (Evgeny Makarenko); Novosibirsk Medical University (Vladimir Kokhno); Omsk Regional Clinical Hospital (Alla Tolkach); Railway Hospital of Khabarovsk (Evgeny Kokarev); St Alexy Hospital (Boris Belotserkovskiy); State District Hospital (Konstantin Zolotukhin); Vishnevsky Institute of Surgery (Vladimir Kulabukhov) Serbia: Clinic for Cardiac Surgery, Clinical Centre of Serbia (Ljiljana Soskic); Clinic for Digestive Surgery, Clinical Centre Serbia (Ivan Palibrk); Clinic for Vascular Surgery, Clinical Centre Nis (Radmilo Jankovic); Clinical Centre of Serbia (Bojan Jovanovic); Clinical Centre of Serbia (Milena Pandurovic); Emergency Centre, Clinical Centre of Belgrade (Vesna Bumbasirevic); General University Hospital (Boris Uljarevic); Military Medical Academy (Maja Surbatovic); Urology Hospital (Nebojsa Ladjevic)

Slovakia: District Hospital (Garri Slobodianiuk); Faculty Hospital (Viliam Sobona); University Hospital Bratislava-Hospital Ruzinov ICU (Andrea Cikova); University Hospital Ruzinov Bratislava (Andrea Gebhardtova)

China: A Tertiary Hospital (Cao Jun); Affiliated Hospital of Medical College Qingdao Universty (Sun Yunbo); Beijing Cancer Hospital,Beijing Institute for Cancer Research (Jun Dong); Beijing Chaoyang Hospital (Sui Feng); Beijing Friendship Hospital (Meili Duan); Beijing Tongren Hospital Affiliate of Capital Medical University (Yuan Xu); Beijing University People's Hospital (Xiaoyan Xue); Beijing Luhe Hospital (Tieying Gao); Cancer Hospital, Chinese Academy of Medical Sciences (XueZhong Xing); China Academy of Chinese Medical Sciences Guang 'An Men Hospital (Xin Zhao); Chuxiong, Yunnan Province, People's Hospital (ChaoHong Li); Donge County People's Hospital of Shandong Province (Gengxihua Gengxihua); Fu Wai Hospital, Chinese Academy of Medical Sciences (Huiqiong Tan); Fujian Provincial Hospital (Jingqing Xu); Fuxing Hospital, Capital Medicine University (Li Jiang); Guangdong General Hospital (Qin Tiehe); Henan Provincial People's Hospital (Qin Bingyu); Xian Jiaotong University College of Medicine (Qindong Shi); Kunming Third People's Hospital (Zheng Lv); Lanzhou University Second Hospital (Liping Zhang); No 309th Hospital (Liu Jingtao); No.1 Hospital of China Medical University (Zheng Zhen); Peking University Shougang Hospital (Zheng Wang); Peking University Third Hospital (Tie Hua Wang); Pla Navy General Hospital (Liu Yuhong); Qilu Hospital Shandong University (Qian Zhai); Ruijin Hospital Affiliated Medical School of Jiaotong University, Shanghai (Ying Chen); Shandong Provincial Hospital (Chunting Wang); Shanghai 10th People's Hospital (Wei Jiang); Shanghai First People's Hospital (Wang Ruilan); Sichuan Provincial People's Hospital (Youdai Chen); Sichuan Provincial People's Hospital (Huang Xiaobo); Sir Run Run Shaw Hospital (Huiqing Ge); The Affiliated of Guiyang Medical College (Tang Yan); The Fifth People's Hospital of Shanghai, Fudan University (Cui Yuhui); The First Affiliated Hospital of Dalian Medical University (Jiuzhi Zhang); The First Affiliated Hospital of Suzhou University (Fu Jian-Hong); The First Affiliated Hospital of Xinjiang Medical University (Hong Zhu); The First Hospital of Jilin University (Feifei Huo); The First Hospital of Jilin University (Yushan Wang); The First People's Hospital of Kunming (Chao Li); The General Hospital of Shenyang Military Region, China (Ma Zhuang); The People's Hospital of Cangzhou
(Zengxiang Ma); The Second Hospital of Jilin University (Jian Sun); The Second People's Hospital of Liaocheng City Shandong Province (Liuqingyue Liuqingyue); The Third Xiangya Hospital (Mingshi Yang); Tongde Hospital of Zhejiang Province (Jianbiao Meng); Tongji University Shanghai East Hospital (Shaolin Ma); West China Hospital, Scu (Yan Kang); Wuhan Centre Hospital (Li Yu); Xiangya Hospital, Changsha, Hunan Province, China (Qianyi Peng); Yantai Yuhuangding Hospital (Yu Wei); Yantaishan Hospital, Shandong Province (Wei Zhang); Zhejiang Provincial People's Hospital (Renhua Sun) Hong Kong (China): Pamela Youde Nethersole Eastern Hospital (Alwin Yeung); Princess Margaret Hospital (Wing Lun Wan); Queen Elizabeth Hospital (K Kai Cheuk Sin); United Christian Hospital of Hong Kong SAR (Kar Lung Lee) Indonesia: Anestesi (Meri Wijanti); Pku Muhammadiyah Bantul, Yogyakarta (Untung Widodo); Rd. Mattaher Hospital Jambi (Halim Samsirun); Rumah Sakit Pantai Indah Kapuk (Tantani Sugiman); Sardjito Hospital (Calcarina Wisudarti); School of Medicine Unpad - Hasan Sadikin Hospital (Tinni T Maskoen)

Japan: Chiba Hokusoh Hospital, Nippon Medical School (Noritaka Hata): Chiba University Hospital (Yoshiro Kobe); Fujita Health University School of Medicine (Osamu Nishida); Japanese Red Cross Maebashi Hospital (Dai Miyazaki); Jichi Medical University Hospital (Shin Nunomiya); Jikei University School of Medicine (Shigehiko Uchino); Kimitsu Chuo Hospital (Nobuya Kitamura); Kochi Medical School (Koichi Yamashita); Kyoto Prefectural University of Medicine (Satoru Hashimoto); Nara Medical University Hospital (Hidetada Fukushima)

Malaysia: Hospital Sultanah Nur Zahirah, Kuala Terengganu, Terengganu, (Nik Azman Nik Adib); Kuala Lumpur Hospital (Li Ling Tai); Queen Elizabeth Hospital 2 (Bill Tony) Philippines: Cebu Velez General Hospital (Rodolfo Roman Bigornia); Chong Hua Hospital (Rodolfo Roman Bigornia); Perpetual Succour Hospital (Rodolfo Roman Bigornia); The Medical City (Jose Emmanuel Palo)

Singapore: Alexandra Hospital (Somnath Chatterjee); National University Health System (Bee Hong Tan); Singapore General Hospital (Andrew Kong); Tan Tock Seng Hospital (Shirley Goh)

Taiwan: National Taiwan University Hospital (Chien-Chang Lee) Thailand: Maharaj Nakorn Chiangmai Hospital, Chiaingmai University (Chaicharn Pothirat); Prince of Songkla University (Bodin Khwannimit); Ramathibodi Hospital (Pongdhep Theerawit); Ramathibodi Hospital, Somdech Phra Debaratana Medical Centre (Prapaporn Pornsuriyasak); Siriraj Hospital, Mahidol University (Annop Piriyapatsom)

Egypt: Cairo University (Ahmed Mukhtar); Demerdash Surgical Intensive Care Unit (Dsicu); Ain Shams Faculty of Medicine (Ahmed Nabil Hamdy); Zaitoun Specialized Hospital (Hisham Hosny)

Iran: Gums (Ali Ashraf); Imam Hossein Hospital, Sbums (Majid Mokhtari); Imamreza Hospital (Shiva Nowruzinia); Laleh Hospital (Amir Hossein Lotfi); Shiraz Anesthesiology and Critical Care Research Center (Farid Zand); Shiraz University of Medical Sciences (Reza Nikandish); Tehran Medical Sciences University (Omid Moradi Moghaddam)

Israel: Rabin Medical Centre (Jonathan Cohen); Sourasky Tel Aviv Medical Centre (Oded Sold).

Lebanon: Centre Hospitalier Du Nord (Tacla Sfeir)

Oman: Sohar Hospital (Alaa Yasin Hasan)

Palestinian Territories: Specialized Arab Hospital (Dena Abugaber)

Saudi Arabia: Almana General Hospital (Habib Ahmad); KFSHRC, Riyadh (Tarek

Tantawy); King Abdulaziz Medical City Riyadh (Salim Baharoom); King

Abdulaziz University (Haifa Algethamy); King Saud Medical City (Anas Amr); Riyadh Military Hospital (Ghaleb Almekhlafi)

Turkey: Erciyes University Medical Faculty (Ramazan Coskun); Erciyes University Medical School (Murat Sungur); Gülhane Military Medical Academy (Ahmet Cosar); International Hospital, Istanbul (Bülent Güçyetmez); Istanbul University Cerrahpasa Medical School Hospital (Oktay Demirkiran); Istanbul University Istanbul Medical Faculty (Evren Senturk); Karadeniz Technical University, Medical Faculty (Hulya Ulusoy); Memorial Atasehir Hospital (Hakan Korkut Atalan); Pamukkale Universty (Simay Serin); Yuzuncu Yil Universitesy Medical Faculty (Ismail Kati)

United Arab Emirates: Dubai Hospital (Zainab Alnassrawi); Mafraq Hospital (Ayesha Almemari); Sheikh Khalifa Medical City (Kalpana Krishnareddy); Tawam Hospital (Sayed Kashef); The City Hospital (Asad Alsabbah) Canada: Hôpital Charles Lemoyne (Germain Poirier); St. Michael's Hospital (John C Marshall); Toronto General Hospital (Margaret Herridge); Toronto Western Hospital (Margaret Herridge)

Puerto Rico: San Juan Hospital (Rosangela Fernandez-Medero) 
United States: Christiana Care Health System (Gerard Fulda); Cincinnati Children's Hospital Medical Centre (Sharon Banschbach); El Camino Hospital (Juan Quintero); George Washington Hospital (Elizabeth Schroeder); Hospital of The University of Pennsylvania (Corinna Sicoutris); John H Stroger Hospital of Cook County (Renaud Gueret); Mayo Clinic, CCM (Rahul Kashyap); Mayo Clinic, PCC (Philippe Bauer); Medical College of Wisconsin (Rahul Nanchal); Northwestern Memorial Hospital (Richard G Wunderink); Orlando Regional Medical Centre (Edgar Jimenez); Washington Hospital Centre (Andrea Ryan) Australia: Armadale Health Service (Denvir Prince); Bendigo Hospital (John Edington); Canberra Hospital (Frank Van Haren); Flinders Medical Centre (Andrew Bersten); Joondalup Health Campus (David J Hawkins); Lismore Base Hospital (Myrene Kilminster); Mater Adult Hospital (David Sturgess); Prince Charles Hospital, Brisbane (Marc Ziegenfuss); Royal Adelaide Hospital (Stephanie O' Connor); Royal Brisbane and Womens' Hospital (Jeffrey Lipman); Royal Darwin Hospital (Lewis Campbell); Royal Hobart Hospital (Rick Mcallister); Sir Charles Gairdner Hospital (Brigit Roberts); The Queen Elizabeth Hospital (Patricia Williams)

New Zealand: Auckland District Health Board (Rachael Parke); Christchurch Hospital (Patrick Seigne); Hawke's Bay Hospital (Ross Freebairn); Midcentral Health, Palmerston North Hospital (Daniel Nistor); Middlemore Hospital (Chantal Oxley); Wellington Hospital (Paul Young)

Argentina: Cemic (Centro De Educación Médica E Investigaciones Clínicas) (Ricardo Valentini); Fleni (Nestor Wainsztein); Hospital Aleman (Pablo Comignani); Hospital Central San Isidro (Maria Casaretto); Hospital Fernandez (Giselle Sutton); Hospital Francisco Lopez Lima Area Programa General Roca (Paula Villegas); Sanatorio Allende (Cayerano Galletti); Sanatorio De La Trinidad Palermo (Jorge Neira); Sanatorio Julio Corzo Rosario (Daniel Rovira) Belize: Karl Heusner Memorial Hospital and Belize Healthcare Partner (Jorge Hidalgo).

Bolivia: Hospital Obrero No1 (Freddy Sandi)

Brazil: Cias -Unimed Vitória (Eliana Caser); Evangelical Hospital of Cachoeiro De Itapemirim (Marlus M Thompson); Hospital 9 De Julho (Mariza D'agostino Dias); Hospital Alcides Carneiro (Luis E Fontes); Hospital Das Clínicas Luzia De Pinho Melo (Maria C Lunardi); Hospital Das Nações De Curitiba (Nazah C Youssef); Hospital De Base Famerp (Suzana Lobo); Hospital De Clínicas De Niterói (Ricardo Silva); Hospital De Clínicas Padre Miguel (Joao A Sales Jr); Hospital De Terapia Intensiva (Lina Madeira Campos Melo); Hospital Do Trabalhador (Mirella Oliveira); Hospital Esperanca (Mariza Fonte); Hospital Evangelico De Londrina (Cintia Grion); Hospital Geral De Fortaleza (Carlos Feijo); Hospital Geral De Roraima (Valaria Rezende); Hospital Israelita Albert Einstein (Murillo Assuncao); Hospital Mater Dei (Ana P Neves); Hospital Meridional (Pablo Gusman); Hospital Meridional (Dyanne Dalcomune); Hospital Moinhos De Vento (Cassiano Teixeira); Hospital Municipal Ruth Cardoso (Keitiane Kaefer); Hospital Nereu Ramos (Israel Maia); Hospital Pasteur (Vicente Souza Dantas); Hospital Pro Cardiaco (Rubens Costa Filho); Hospital Regional De Samambaia (Fabio Amorim); Hospital Regional Hans Dieter Schmidt (Maria Assef); Hospital Santa Casa - Campo Mourão (Paulo Schiavetto); Hospital Santa Paula (Joao Houly); Hospital São José Do Avaí (Fabiano Bianchi); Hospital São Lucas Da Pucrs (Fernando Dias); Hospital Sao Vicente De Paula (Carla Avila); Hospital Saude Da Mulher (Leila Rego); Hospital Tacchini (Priscylla Castro); Hospital Unimed Costa Do Sol-Macae-Rj (Joel Passos); Hospital Universitário - Ufpb - João Pessoa (Ciro Mendes); Hospital Universitário De Londrina (Cintia Grion); Hospital Universitário São Francisco (Giovana Colozza Mecatti); Santa Casa De Caridade De Diamantina (Marcia Ferrreira); Santa Casa De Misericordia De Tatui (Vivian Irineu); São Francisco De Paula Hospital (Marcio Guerreiro)

Chile: Clinica Indisa (Sebastian Ugarte); Clinica Las Lilas (Vinko Tomicic); Hospital Carlos Van Buren (Christian Godoy); Hospital Del Trabajador De Santiago (Wagner Samaniego); Hospital El Pino (Ignacio Escamilla); Hospital Mutual De Seguridad (Ignacio Escamilla)

Colombia: Centro Medico Imbanaco (Luis F Castro Castro); Clinica Colombia Cali (Giovanni Libreros Duque); Clínica Del Café (Diego Diaz-Guio); Clínica La Estancia S.A. (Frederico Benítez); Clinica Medellin (Arturo Guerra Urrego); Fundacion Clinica Shaio (Ricardo Buitrago); Hospital Santa Clara (Guillermo Ortiz); Hospital Universitario Fundación Santa Fe De Bogota (Maria C Villalba Gaviria)

Costa Rica: Calderón Guardia Hospital (Donat Salas); Hospital Dr. Rafael Angel Varlderon Guardia CCSS (Jorge Ramirez-Arce)

Ecuador: Clinica La Merced (Estuardo Salgado); Hospital Eugenio Espejo (Diego Morocho); Hospital Luis Vernaza (Jose Vergara); Shdug Sistema Hospitalario Docente De La Universidad De Guayaquil (Miguel Chung Sang)
El Salvador: General Hospital (Carlos Orellana-Jimenez) Guatemala: Hospital Centro Medico (Lorena Garrido) Honduras: Instituto Hondureño Del Seguro Social (Oscar Diaz) Martinique: Centre Hospitalier Universitaire De Fort-De-France (Dabor Resiere) Mexico: Centro Estatal De Cuidados Críticos (Carlos Osorio); Centro Médico Nacional "20 De Noviembre" ISSSTE (Alberto De La Vega); Fundacion Clinica Medica Sur (Raul Carrillo); Hospital San Jose TEC Monterrey (Victor Sanchez); Hospital 1o De Octubre, ISSSTE (Asisclo Villagomez); Hospital Español De Mexico (Ricardo Martinez Zubieta); Hospital General Ajusco Medio (Maria Sandia); Hospital General Guadalupe Victoria (Maycotte Zalatiel); Hospital Juarez De Mexico (Manuel Poblano); Hospitalcivil De Guadalajara, Hspitaljuan I Menchaca (Daniel Rodriguez Gonzalez); Instituto Mexicano Del Seguro Social (Fernando Arrazola); Instituto Mexicano Del Seguro Social (Leal L Juan Francisco); Instituto Nacional de Cancerología, México (Silvio A ÑamendysSilva); ISSSTE (Rosalinda Guerra Moya); Medical Centre ISSEMYM Toluca (Marco Hernandez); Mixta (Diego M Rodriguez Cadena); Secretaria De Salud Del Distrito Federal (Ines Lopez Islas)

Panama: Hospital Santo Tomás (Carlos M Ballesteros Zarzavilla); Social Security Hospital (Alfredo Matos)

Peru: Clinica Anglo Americana (Indira Oyanguren); ESSALUD (Jorge Cerna); Hospital Nacional Dos De Mayo (Rosario Quispe Sierra); Hospital Rebagliati (Rocio Jimenez); Instituto Nacional De Enfermedades Neoplasicas (Luis Castillo)

Turks And Caicos Islands: Gulhane Medical Faculty (Ramizan Ocal); Izmir Atatürk Educational And Research Hosp. (Atilla Sencan)

Uruquay: CAMS (Silvia M Mareque Gianoni); CASMU (Alberto Deicas); Hospital Español Asse (Javier Hurtado); Hospital Maciel (Gaston Burghi) Venezuela: Centro Medico De Caracas (Antonio Martinelli); Hospital Miguel Perez Carreño (Ingrid Von Der Osten) Afghanistan: MSF Trauma Hospital Kunduz (Christine Du Maine) India: Amri Hospitals (Mahuya Bhattacharyya); Amri Hospitals Salt Lake (Susruta Bandyopadhyay); Apollo Hospital (Srishar Yanamala); Apollo Hospitals (Palepu Gopal); Apollo Hospitals, Bhubaneswar (Samir Sahu); Apollo Speciality Hospital (Mohamed Ibrahim); Asian Heart Institute (Darshana Rathod); Baby Memorial Hospital Ltd., Calicut, Kerala (Nisha Mukundan); Batra Hospital \& Mrc, New Delhi (Arun Dewan); Bombay Hospital Institute of Medical Sciences (Pravin Amin); Care Hospital (Srinivas Samavedam); Cims Hospital (Bhagyesh Shah); Columbia Asia Hospital, Mysore (Ganavelu Gurupal); Dispur Hospitals (Brajendra Lahkar); Fortis Hospital (Amit K Mandal); Fortis Hospital (Noida) (Mrinal Sircar); Fortis-Escorts Hospital, Faridabad (Supradip Ghosh); Ganga Medical Centre \& Hospital P Ltd. (Veluchamy Balasubramani); Hinduja Hospital (Farhad Kapadia); KDAH (Sonali Vadi); Kerala Institute of Medical Sciences (KIMS, RMCC) (Kesavan Nair); Kalinga Institute of Medical Sciences (KIMS, DTEM) (Swagat Tripathy); Kovai Medical Centre and Hospital (Sivakumar Nandakumar); Medanta The Medicity, Gurgaon (Jeetendra Sharma); Medica Superspecialty Hospitals (Arindam Kar); Metro Heart Institute with Multispeciality (Simant Jha); Ruby Hall Pune (Kapil Zirpe); Saifee Hospital (Mayur Patel); Spandan Multispeciality Hospital (Ankur Bhavsar); Tata Main Hospital (Devi P Samaddar); Tata Memorial Hospital (Atul Kulkarni) Pakistan: Aga Khan University (Madiha Hashmi); Hearts International Hospital (Wajid Ali); Liaquat National Hospital (Syed Nadeem)

Sri Lanka: Sri Jayewardenepura General Hospital (Kanishka Indraratna) Andorra: Hospital Nostra Senyora De Meritxell (Antoni Margarit) Austria: Akh Wien (Philipp Urbanek); Allgemeines Und Orthopädisches Landeskrankenhaus Stolzalpe (Joachim Schlieber); Barmherzige Schwestern Linz (Johann Reisinger); General Hospital Braunau (Johann Auer); Krankenhaus D. Barmherzigen Schwestern Ried I.I. (Andreas Hartjes); Krankenhaus Floridsdorf (Andreas Lerche); LK Gmünd-Waidhofen/ThayaZwettl, Standort Zwettl (Thomas Janous); LKH Hörgas-Enzenbach (Eveline Kink); LKH West (Walter Krahulec); University Hospital (Karl-Heinz Smolle) Belgium: AZ Groeninge Kortrijk (Marc Van Der Schueren); AZ Jan Palfijn Gent (Patrick Thibo); AZ Turnhout (Marc Vanhoof); Bracops Anderlecht (Ibis Ahmet); Centre Hospitalier Mouscron (Philippe Gadisseux); CH Peltzer La Tourelle (Philippe Dufaye); Chirec Edith Cavell (Olivier Jacobs); CHR Citadelle (Vincent Fraipont); CHU Charleroi (Patrick Biston); Chu Mont-Godinne (Alain Dive); CHU Tivoli (Yves Bouckaert); Chwapi (Eric Gilbert); Clinique Saint-Pierre Ottignies (Benjamin Gressens); Clinique-Maternité Sainte Elisabeth (Eric Pinck); Cliniques De L'Europe - St-Michel (Vincent Collin); Erasme University Hospital (Jean-Louis Vincent); Ghent University Hospital (Jan J De Waele); Moliere Hospital (Rocio Rimachi); Notre Dame (Dan Gusu); Onze Lieve Vrouw Ziekenhuis, Aalst (Koen De Decker); Ixelles Hospital (Kakisidi Mandianga); Sint-Augustinus 
(Luc Heytens); St Luc University Hospital (UCL) (Xavier Wittebole); UZ Brusse (Herbert Spapen); Vivalia Site De Libramont (Olivier Van Collie); VZW Gezondheidszorg Oostkust Knokke-Heist (Wout Vandenheede); ZNA Middelheim (Peter Rogiers)

Denmark: Herning Hospital (Piotr Kolodzeike); Hjoerring Hospital (Mary Kruse); Vejle Hospital (Torben Andersen)

Finland: Helsinki University Central Hospital (Veli-Pekka Harjola); Seinäjoki Central Hospital (Kari Saarinen)

France: Aix Marseille Univ, Hôpital Nord (Marc Leone); Calmette Hospital, Lille (Alain Durocher); Centre Hospitalier de Dunkerque (Serge Moulront); Centre Hospitalier Lyon Sud (Alain Lepape); Centre Hospitalo-Universitaire NancyBrabois (Marie-Reine Losser); CH Saint Philibert, Ghicl, Lille (Philippe Cabaret); CHR De Dax (Evangelos Kalaitzis); CHU Amiens (Elie Zogheib); CHU Dijon (Philippe Charve); CHU Dupuytren, Limoges (Bruno François); CHU Nîmes (Jean-Yves Lefrant); Centre Hospitalier De Troyes (Bassam Beilouny); Groupe Hospitalier Est Francilien-Centre Hospitalier De Meaux (Xavier Forceville); Groupe Hospitalier Paris Saint Joseph (Benoit Misset); Hopital Antoine Béclère (Frederic Jacobs); Hopital Edouard Herriot (Bernard Floccard); Hôpital Lariboisère, APHP, Paris France (Didier Payen); Hopital Maison Blanche, Reims (Alain Wynckel); Hopitaux Universitaires de Strasbourg (Vincent Castelain); Hospices Civils de Lyon (Alexandre Faure); CHU-Grenoble (Pierre Lavagne); CHUNantes (Thierry Lepoivre); Réanimation Chirurgical Cardiovasculaire, CHRU Lille (Mouhamed D Moussa); University Hospital Ambroise Paré (Antoine Vieillard-Baron); University Hospital Grenoble (Michel Durand); University Hospital of Marseille (Marc Gainnier); University of Nice (Carole Ichai) Germany: Alexianer Krefeld Gmbh (Stefan Arens); Charite Hochschulmedizin Berlin (Clemens Hoffmann); Charite-University-Hospital, Berlin (Magnus Kaffarnik); Diakoniekrankenhaus Henriettenstiftung Gmbh (Claus-Jorg Scharnofske); Elisabeth-Krankenhaus, Essen (Ingo Voigt); Harlaching Hospital, Munich Municipal Hospital Group (Claus Peckelsen); Helios St. Johannes Klinik (Matthias Weber); Hospital St. Georg Leipzig (Jochen Gille); Klinik Hennigsdorf Der Oberhavel Kliniken Gmbh (Andreas Lange); Klinik Tettnang (Georg Schoser); Klinikum "St. Georg" Leipzig (Armin Sablotzki); Klinikum Augsburg (Ulrich Jaschinski); Klinikum Augsburg (Andreas Bluethgen); Klinikum Bremen-Mitte (Frank Vogel); Klinikum Bremen-Ost (Andreas Tscheu); Klinikum Heidenheim (Thomas Fuchs); Klinikum Links Der Weser Gmbh (Michael Wattenberg); Klinikum Luedenscheid (Torsten Helmes); Krankenhaus Neuwerk (Stefan Scieszka); Marienkrankenhaus Schwerte (Matthias Heintz); Medical Centre Cologne Merheim (Samir Sakka); Schwarzwald-Baar Klinikum Villingen-Schwenningen (Johannes Kohler); St. Elisabeth Krankenhaus Köln-Hohenlind (Fritz Fiedler); St. Martinus Hospital Olpe (Matthias Danz); Uniklinikum Jena (Yasser Sakr); Universitätsklinikum Tübingen (Reimer Riessen); Universitätsmedizin Mainz (Thomas Kerz); University Hospital Aachen, CPACC (Alexander Kersten); University Hospital Aachen, DMIII (Frank Tacke); University Hospital Aachen, OIC (Gernot Marx); University Hospital Muenster (Thomas Volkert); University Medical Centre Freiburg (Axel Schmutz); University Medical Centre HamburgEppendorf (Axel Nierhaus); University Medical Centre Hamburg-Eppendorf (Stefan Kluge); University Medicine Greifswald (Peter Abel); University of Duisburg-Essen (Rolf A Janosi); University of Freiburg (Stefan Utzolino); University clinic UIm (Hendrik Bracht); Vivantes Klinikum Neukoelln (Susanne Toussaint)

Greece: Ahepa University Hospital (Maria Giannakou Peftoulidou); Athens University (Pavlos Myrianthefs); Athens University Medical School (Apostolos Armaganidis); Evangelismos Hospital (Christina Routsi); General Hospital of Chania, Crete (Angela Xini); Hippokration General Hospital, Thessaloniki (Eleni Mouloudi); General hospital of Velos (loannis Kokoris); Lamia General Hospital (George Kyriazopoulos); Naval and Veterans Hospital (Sawas Vlachos); Papanikolaou General Hospital (Athena Lavrentieva); University Hospital Alexandroupolis (Panagio Partala); University of Ioannina (George Nakos) Iceland: Landspitali University Hospital (Alma Moller); Landspitali University Hospital Fossvogur (Sigurjon Ö Stefansson)

Ireland: Cork University Hospital (Joan Barry); Mercy University Hospital (Ruth A O'Leary); Mid Western Regional Hospital Complex (Catherine Motherway); Midland Regional Hospital Mullingar, Co Westmeath (Mohammad Faheem); St. Vincent's University Hospital (Eimhin Dunne); Tallaght Hospital (Maria Donnelly); University Hospital Galway (Torsten Konrad) Italy: Anesthesiology and Intensive Care (Eleonora Bonora); AO Ospedale Niguarda Ca' Granda (Carola Achilli); Azienda Ospedaliera Di Padova (Sandra Rossi); Azienda Ospedaliero Universitaria Policlinico Vittorio Emanuele (Giacomo Castiglione); Careggi Teaching Hospital (Adriano Peris); Clinicized Hospital SS Annunziata - Chieti (Daniela Albanese); Fondazione IRCCS Ca'
Granda Ospedale Maggiore Policlinico, Milano; University of Milan (Nino Stocchetti); H San Gerardo - Monza (Giuseppe Citerio); ICU "Ceccarini" Hospital Riccione (Lorella Mozzoni); IRCCS Centro Cardiologico Monzino (Erminio Sisillo); IRCCS Centro Di Riferimento Oncologico Della Basilicata (Pasquale De Negri); IRCCS Fondazione Ca' Granda - Ospedale Maggiore Policlinico (Monica Savioli); Ospedale Belcolle Viterbo (Pietro Vecchiarelli); Ospedale Civile Maggiore - A.O.U.I Verona (Florin Puflea); Ospedale Civile Maggiore - A.O.U.I Verona (Vladimir Stankovic); Ospedale Di Circolo E Fondazione Macchi - Varese (Giulio Minoja); Ospedale Di Trento - Azienda Provinciale Per I Servizi Sanitari Della Provincia Autonoma Di Trento (Silvia Montibeller); Ospedale Orlandi (Plinio Calligaro); Ospedale Regionale U.PariniAosta (Raffaella Sorrentino); Ospedale San Donato Arezzo (Marco Feri); Ospedale San Raffaele (Massimo Zambon); Policlinico G.B. Rossi - A.O.U.I Verona (Elena Colombaroli); Policlinico University of Palermo (Antonino Giarratano); Santa Maria Degli Angeli Hospital (Tommaso Pellis); Saronno Hospital (Carlo Capra); Università Cattolica Del Sacro Cuore (Massimo Antonelli); University Catania, Italy (Antonino Gullo); University of Florence, Florence (Cosimo Chelazzi); University of Foggia (Antonella De Capraris); University of Milano-Bicocca, San Gerardo Hospital (Nicolo Patroniti); University of Modena (Massimo Girardis); University of Siena (Frederico Franchi); University of Trieste (Giorgio Berlot)

Malta: Mater Dei Hospital (Michael Buttigieg)

Netherlands: Albert Schweitzer Hospital (Hubert Ponssen); Antoni Van Leeuwenhoek Ziekenhuis (Julia Ten Cate); Atrium Medisch Centrum Parkstad (Laura Bormans); Bovenij Hospital (Satria Husada); Catharina Hospital Eindhoven (Marc Buise); Erasmus University Medical Centre (Ben Van Der Hoven); Martiniziekenhuis Groningen (Auke Reidinga); Medical Centre Leeuwarden (Michael Kuiper); Radboud University Nijmegen Medical Centre (Peter Pickkers); Slotervaart Ziekenhuis Amsterdam (Georg Kluge); Spaarne Ziekenhuis (Sylvia Den Boer); University Medical Centre Utrecht (Jozef Kesecioglu); Ziekenhuis Rijnstate (Henk Van Leeuwen)

Norway: Haukeland University Hospital (Hans Flaatten); St Olavs Hospital, Trondheim University Hospital (Skule Mo)

Portugal: Centro Hospitalar Cova Da Beira (Vitor Branco); Centro Hospitalar Do Porto (Fernando Rua); Centro Hospitalar Do Tâmega E Sousa (Estevao Lafuente); Centro Hospitalar Gaia/Espinho, Epe (Marta Sousa); Centro Hospitalar Médio Tejo (Nuno Catorze); Centro Hospitalar Tondela-Viseu (Maria Barros); Faro Hospital (Luis Pereira); Hospital Curry Cabral (Ana Vintém De Oliveira); Hospital Da Luz (Jose Gomes); Hospital De Egas Moniz - Chlo (Isable Gaspar); Hospital De Santo António, Centro Hospitalar Do Porto (Maria F Pereira); Hospital Divino Espírito Santo, Epe (Maria Cymbron); Hospital Espirito Santo - Évora Epe (Antonio Dias); Hospital Garcia Orta (Eduardo Almeida); Hospital Geral Centro Hospitalar E Universitario Coimbra (Sofia Beirao); Hospital Prof. Doutor Fernando Fonseca Epe (Isabel Serra); Hospital São Bernardo (Rosa Ribeiro); Hospital Sao Francisco Xavier, Chlo (Pedro Povoa); Instituto Portugues De Oncologia Francisco Gentil, Porto (Filomena Faria); Santa Maria Hospital (Zelia Costa-E-Silva); Serviço De Saúde Da Região Autonóma Da Madeira (Jose J Nóbrega); UCIP (Fatima Fernandes); ULS - Castelo Branco (Joao Gabriel)

Slovenia: General Hospital Celje (Gorazd Voga); General Hospital Izola (Erik Rupnik); General Hospital Novo Mesto (Lucka Kosec); Oncological Institute (Milena Kerin Povšic); Ukc Maribor (Irena Osojnik); University Clinic of Respiratory and Allergic Diseases (Viktorija Tomic); University Clinical Centre Maribor (Andreja Sinkovic)

Spain: CH Salamanca (Javier González); Clinic Hospital (Elizabeth Zavala); Complejo Hospitalario De Jaén (Jesus Pérez Valenzuela); Complejo. Hospitalario De Toledo (Luis Marina); Complexo Hospitalario Universitario De Ourense (Pablo Vidal-Cortés); Complexo Hospitalario Universitario De Vigo (Pilar Posada); Corporación Sanitaria Parc Tauli (Ignacio Martin-Loeches); Cruz Roja Hospital (Noelia Muñoz Guillén); H Vall Hebron (Mercedes Palomar); HGGC Dr. Negrín (Jordi Sole-Violan); Hospital Clinic (Antoni Torres); Hospital Clinico San Carlos (Miguel A Gonzalez Gallego); Hospital Clínico Universitario De Valencia (Gerardo Aguilar); Hospital Clínico Universitario Lozano Blesa (Raquel Montoiro Allué); Hospital Clinico Valencia (Monica Argüeso); Hospital De La Ribera (Martin Parejo); Hospital De Sagunto (Manuel Palomo Navarro); Hospital De San Juan De Alicante (Anton Jose); Hospital De Torrejon De Ardoz (Nicholas Nin); Hospital Del Mar (Francisco Alvarez Lerma); Hospital Del Tajo (Oscar Martinez); Hospital General Universitario De Elche (Eva Tenza Lozano); Hospital General Universitario Gregorio Marañon (Sara Arenal López); Hospital General Universitario Gregorio Marañon (Maria J Perez Granda); Hospital General Universitario Santa Lucía (Salvador Moreno); 
Hospital Germans Trias I Pujol (Clara Llubia); Hospital Infanta Margarita (Carmen De La Fuente Martos); Hospital Infanta Sofia (Paloma Gonzalez-Arenas); Hospital J.M. Morales Meseguer (Noemi Llamas Fernández); Hospital J.M. Morales Meseguer (Bernard Gil Rueda); Hospital Marina Salu. Denia. Alicante (Isabel Estruch Pons); Hospital Nuestra Señora Del Prado, Talavera De La Reina, Toledo. España (Nieves Cruza); Hospital San Juan De Dios Aljarafe (Fernando Maroto); Hospital Sas of Jerez (Angel Estella); Hospital Son Llatzer (Ana Ferrer); Hospital Universitario Central De Asturias (Lisardo Iglesias Fraile); Hospital Universitario Central De Asturias (Brigida Quindos); Hospital Universitario De Alava, Santiago (Amaia Quintano); Hospital Universitario De Basurto, Bilbao (Maria T Tebar); Hospital Universitario de Getafe (Pablo Cardinal); Hospital Universitario De La Princesa (Antonio Reyes); Hospital Universitario de Tarragona Joan Xxiii (Alejandro Rodríguez); Hospital Universitario Del Henares (Ana Abella); Hospital Universitario Fundación Alcorcón (Santiago García Del Valle); Hospital Universitario La Paz (Santiago Yus); Hospital Universitario La Paz (Emilio Maseda); Hospital Universitario Rio Hortega (Jose A Berezo); Hospital Universitario San Cecilio (Granada) (Armando Tejero Pedregosa); Hospital Virgen Del Camino (Clara Laplaza); Mutua Terrassa University Hospital (Ricard Ferrer); Rão Hortega University Hospital (Jesus Rico-Feijoo); Servicio Andaluz De Salud (Marina Rodríguez); University Okalingaf Navarra (Pablo Monedero)

Sweden: Karolinska University Hospital And Karolinska Institute (Karin Eriksson); Sunderby Hospital, Luleå (Dan Lind) Switzerland: Hôpital Intercantonal De La Broye (David Chabanel); Hôpital Neuchâtelois - La Chaux-De-Fonds (Hervé Zender); Lindenhofspital (Kuno Heer); Regionalspital Surselva llanz (Gr) Schweiz (Bernd Frankenberger); University Hospital Bern (Stephan Jakob); Zentrum Für Intensivmedizin (Alois Haller)

United Kingdom: Alexandra Hospital Redditch (Shiju Matthew); Blackpool Teaching Hospitals (Robert Downes); Brighton And Sussex University Hospitals (Casiano Barrera Groba); Cambridge University Hospitals NHS Foundation Trust (Andrew Johnston); Charing Cross Hospital (Roseanne Meacher); Chelsea \& Westminster Hospital (Rick Keays); Christie Foundation Trust (Philip Haji-Michael); County Hospital, Lincoln (Chris Tyler); Craigavon Area Hospital (Andrew Ferguson); Cumberland Infirmary (Simon Jones); Darent Valley Hospital (David Tyl); Dorset County Hospital (Andrew Ball); Ealing Hospital NHS Trust (John Vogel); Glasgow Royal Infirmary (Malcolm Booth); Gloucester Royal Hospital (Paul Downie); The Great Western Hospital, Swindon (Malcolm Watters); Imperial College Healthcare NHS Trust (Stephen Brett); Ipswich Hospital NHS Trust (Marc Garfield); James Paget University Hospital NHS Foundation Trust (Lynn Everett); King's College Hospital (Sarah Heenen); King's Mill Hospital (Sandeep Dhir); Leeds Teaching Hospitals NHS Trust (Zoe Beardow); Lewisham Healthcare NHS Trust (Marthinus Mostert); Luton and Dunstable Hospital NHS Trust (Steve Brosnan); Medway Maritime Hospital (Nuno Pinto); Musgrove Park Hospital (Stephen Harris); Nevill Hall Hospital (Andy Summors); Pilgrim Hospital (Andrew Norton); Pinderfields Hospital, Mid Yorkshire NHS Trust (Alastair Rose); Plymouth Hospitals NHS Trust (Rebecca Appelboam); Princess Royal Hospital Telford (Omubo Davies); Royal Bournemouth Hospital (Emma Vickers); Royal Free Hampstead NHS Foundation Trust (Banwari Agarwal); Royal Glamorgan Hospital (Tamas Szakmany); Royal Hampshire County Hospital (Stephen Wimbush); Royal Liverpool University Hospital (Ingeborg Welters); Royal London Hospital, Barts Health NHS Trust (Rupert Pearse); Royal Shrewsbury Hospital (Robin Hollands); Royal Surrey County Hospital (Justin Kirk-Bayley); St Georges Healthcare (Nick Fletcher); Surrey \& Sussex Healthcare Trust (Barbara Bray); University College Hospital (David Brealey); University Hospital of South Manchester (Peter Alexander); Western Infirmary (Steven Henderson); Whittington Hospital (Chris Hargreaves); Wirral University Teaching Hospital (Heather Black); Yeovil District Hospital (Kiran Gowda)

\section{Authors' contributions}

JLV conceived and participated in the original study, collected and analyzed the data, drafted this manuscript, and approved the submitted version of the manuscript. AF participated in the original study, revised the manuscript for critical content, and approved the submitted version of the manuscript. PP participated in the original study, revised the manuscript for critical content, and approved the submitted version of the manuscript. SMJ participated in the original study, revised the manuscript for critical content, and approved the submitted version of the manuscript. UJ participated in the original study, revised the manuscript for critical content, and approved the submitted version of the manuscript. GAA participated in the original study, revised the manuscript for critical content, and approved the submitted version of the manuscript. ML participated in the original study, revised the manuscript for critical content, and approved the submitted version of the manuscript. MM participated in the original study, revised the manuscript for critical content, and approved the submitted version of the manuscript. LEF participated in the original study, revised the manuscript for critical content, and approved the submitted version of the manuscript. PB participated in the original study, revised the manuscript for critical content, and approved the submitted version of the manuscript. YS helped conceive the original study, participated in the original study, and revised the manuscript for critical content, and approved the submitted version of the manuscript.

\section{Funding}

None

\section{Availability of data and materials}

The datasets used and/or analyzed during the current study are available from the corresponding author on reasonable request.

\section{Ethics approval and consent to participate}

Ethics committee approval was obtained by the participating institutions according to local ethical regulations.

\section{Consent for publication}

Not applicable

\section{Competing interests}

Marc Leone reports receiving consulting fees from Amomed and Aguettant; lecture fees from MSD, Pfizer, Octapharma, 3 M, Aspen, Orion; travel support from LFB; and grant support from PHRC IR and his institution.

JLV is the Editor-in-Chief of Critical Care.

The other authors declare that they have no relevant financial interests.

\section{Author details}

${ }^{1}$ Department of Intensive Care, Erasme University Hospital, Université Libre de Bruxelles, Route de Lennik, 808, 1070 Brussels, Belgium. ${ }^{2}$ Department of Intensive Care Medicine, Belfast City Hospital, Belfast, UK. ${ }^{3}$ Department of Intensive Care Medicine, Radboud University Medical Center, Nijmegen, The Netherlands. ${ }^{4}$ Department of Intensive Care Medicine, University Hospital Bern, University of Bern, Bern, Switzerland. ${ }^{5}$ Klinik für Anästhesiologie und Operative Intensivmedizin, Universitätsklinik Augsburg, Universität Augsburg, Augsburg, Germany. ${ }^{6}$ ICS Department, Prince Sultan Military Medical City, Riyadh, Saudi Arabia. ${ }^{7}$ Service d'Anesthésie et de Réanimation, APHM, Hôpital Nord, Aix Marseille Université, Marseille, France. ${ }^{8}$ Department of Internal Medicine, SBMU, Tehran, Iran. ${ }^{9}$ Departamento de Medicina Baseada em Evidências, Medicina Intensiva, Urgência e Emergência - Faculdade de Medicina de Petrópolis, Petrópolis, Brazil. ${ }^{10}$ Department of Internal Medicine, Division of Pulmonary and Critical Care Medicine, Mayo Clinic, Rochester, MN, USA. " 1 Departament of Anaesthesiology and Intensive Care, Uniklinikum Jena, Jena, Germany.

\section{Received: 28 October 2019 Accepted: 30 March 2020}

Published online: 23 April 2020

\section{References}

1. Macedo E, Malhotra R, Bouchard J, Wynn SK, Mehta RL. Oliguria is an early predictor of higher mortality in critically ill patients. Kidney Int. 2011:80:760-7.

2. Prowle JR, Liu YL, Licari E, Bagshaw SM, Egi M, Haase M, et al. Oliguria as predictive biomarker of acute kidney injury in critically ill patients. Crit Care. 2011;15:R172.

3. Vaara ST, Parviainen I, Pettila V, Nisula S, Inkinen O, Uusaro A. Association of oliguria with the development of acute kidney injury in the critically ill. Kidney Int. 2016;89:200-8.

4. Kidney Disease Outcomes Quality Initiative. KDIGO clinical practice guidelines for acute kidney injury. Kidney Int Suppl. 2012;2:1-138.

5. Vincent IL, Moreno R, Takala J, Willatts S, de Mendonca A, Bruining H, et al. The SOFA (Sepsis-related Organ Failure Assessment) score to describe organ dysfunction/failure. On behalf of the Working Group on Sepsis-Related Problems of the European Society of Intensive Care Medicine. Intensive Care Med. 1996;22:707-10. 
6. Bellomo R, Ronco C, Kellum JA, Mehta RL, Palevsky P. Acute renal failure definition, outcome measures, animal models, fluid therapy and information technology needs: the Second International Consensus Conference of the Acute Dialysis Quality Initiative (ADQI) Group. Crit Care. 2004:8:R204-12.

7. Mehta RL, Kellum JA, Shah SV, Molitoris BA, Ronco C, Warnock DG, et al. Acute kidney injury network: report of an initiative to improve outcomes in acute kidney injury. Crit Care. 2007;11:R31.

8. Kellum JA, Sileanu FE, Murugan R, Lucko N, Shaw AD, Clermont G. Classifying AKI by urine output versus serum creatinine level. J Am Soc Nephrol. 2015;26:2231-8.

9. Mandelbaum T, Lee J, Scott DJ, Mark RG, Malhotra A, Howell MD, et al. Empirical relationships among oliguria, creatinine, mortality, and renal replacement therapy in the critically ill. Intensive Care Med. 2013;39:414-9.

10. Leedahl DD, Frazee EN, Schramm GE, Dierkhising RA, Bergstralh EJ, Chawla $\mathrm{LS}$, et al. Derivation of urine output thresholds that identify a very high risk of AKI in patients with septic shock. Clin J Am Soc Nephrol. 2014;9:1168-74.

11. Md RA, Pickering JW, Shaw GM, Endre ZH. The urine output definition of acute kidney injury is too liberal. Crit Care. 2013;17:R112.

12. Vincent JL, Marshall JC, Namendys-Silva SA, Francois B, Martin-Loeches I, Lipman J, et al. Assessment of the worldwide burden of critical illness: the intensive care over nations (ICON) audit. Lancet Respir Med. 2014;2:380-6.

13. Gall L Jr, Lemeshow S, Saulnier F. A new Simplified Acute Physiology Score (SAPS II) based on a European/North American multicenter study. JAMA. 1993;270:2957-63.

14. Calandra T, Cohen J. The international sepsis forum consensus conference on definitions of infection in the intensive care unit. Crit Care Med. 2005;33: 1538-48.

15. Singer M, Deutschman CS, Seymour CW, Shankar-Hari M, Annane D, Bauer $M$, et al. The third international consensus definitions for sepsis and septic shock (Sepsis-3). JAMA. 2016;315:801-10.

16. The World Bank. GNI per capita, Atlas method (current US\$). Available at: http://data.worldbank.org/indicator/NY.GNP.PCAP.CD . Accessed 15 Mar 2020.

17. Martin-Loeches I, Njimi H, Vincent JL. Collinearity and multivariable analysis: response to comments by Claret et al. Intensive Care Med. 2016:42:1835.

18. Cordova-Sanchez BM, Herrera-Gomez A, Namendys-Silva SA. Acute kidney injury classified by serum creatinine and urine output in critically ill cancer patients. Biomed Res Int. 2016;2016:6805169

19. Zhang $Z, X u X, N i H$, Deng $H$. Urine output on ICU entry is associated with hospital mortality in unselected critically ill patients. J Nephrol. 2014;27:65-71.

20. Peters E, Antonelli M, Wittebole X, Nanchal R, Francois B, Sakr Y, et al. A worldwide multicentre evaluation of the influence of deterioration or improvement of acute kidney injury on clinical outcome in critically ill patients with and without sepsis at ICU admission: results from The Intensive Care Over Nations audit. Crit Care. 2018:22:188.

21. Mizota T, Yamamoto Y, Hamada M, Matsukawa S, Shimizu S, Kai S. Intraoperative oliguria predicts acute kidney injury after major abdominal surgery. Br J Anaesth. 2017;119:1127-34.

22. Myles PS, Mcllroy DR, Bellomo R, Wallace S. Importance of intraoperative oliguria during major abdominal surgery: findings of the restrictive versus liberal fluid therapy in major abdominal surgery trial. Br J Anaesth. 2019;122: 726-33.

23. da Hora PR, Ramos JGR, Gobatto A, Caldas J, Macedo E, Batista PB. Inclusion and definition of acute renal dysfunction in critically ill patients in randomized controlled trials: a systematic review. Crit Care. 2018;22:106.

24. Perner A, Prowle J, Joannidis M, Young P, Hjortrup PB, Pettila V. Fluid management in acute kidney injury. Intensive Care Med. 2017;43:807-15.

25. Vaara ST, Korhonen AM, Kaukonen KM, Nisula S, Inkinen O, Hoppu S, et al. Fluid overload is associated with an increased risk for 90-day mortality in critically ill patients with renal replacement therapy: data from the prospective FINNAKI study. Crit Care. 2012;16:R197.

26. Sakr Y, Rubatto Birri PN, Kotfis K, Nanchal R, Shah B, Kluge S, et al. Higher fluid balance increases the risk of death from sepsis: results from a large international audit. Crit Care Med. 2017:45:386-94.

27. Rowan KM, Angus DC, Bailey M, Barnato AE, Bellomo R, Canter RR, et al. Early, goal-directed therapy for septic shock - a patient-level meta-analysis. N Engl J Med. 2017;376:2223-34.

\section{Publisher's Note}

Springer Nature remains neutral with regard to jurisdictional claims in published maps and institutional affiliations.

\section{Ready to submit your research? Choose BMC and benefit from}

- fast, convenient online submission

- thorough peer review by experienced researchers in your field

- rapid publication on acceptance

- support for research data, including large and complex data types

- gold Open Access which fosters wider collaboration and increased citations

- maximum visibility for your research: over $100 \mathrm{M}$ website views per year

At BMC, research is always in progress.

Learn more biomedcentral.com/submissions 